\title{
RESEARCH
}

Open Access

\section{Machine learning-selected variables associated with CD4 T cell recovery under antiretroviral therapy in very advanced HIV infection}

Dámaris P. Romero-Rodríguez ${ }^{1 \dagger}$, Carlos Ramírez ${ }^{2 \dagger}$, Iván Imaz-Rosshandler ${ }^{3}$, Christopher E. Ormsby ${ }^{4}$, Amy Peralta-Prado ${ }^{4}$, Gustavo Olvera-García ${ }^{5}$, Fernanda Cervantes ${ }^{5}$, Daniela Würsch-Molina ${ }^{5}$, Jessica Romero-Rodríguez ${ }^{5}$, Wei Jiang ${ }^{6}$, Gustavo Reyes-Terán ${ }^{4}$ and Enrique Espinosa ${ }^{5^{*}}$

\begin{abstract}
Background: A considerable portion of the HIV pandemic is composed of people under antiretroviral therapy, many of whom get a late diagnosis. Patients starting antiretroviral therapy (ART) at a very advanced stage of HIV disease attain a low recovery of CD4 T cells. Factors associated with poor recovery are incompletely described. This study aimed at finding variables associated with CD4 T cell recovery in late-presenting HIV patients.

Methods: We studied a cohort of $\mathrm{HIV}^{+}$patients initiating ART with very low basal CD4 T cell counts. We defined immune recovery as the net increase in circulating CD4 T cell counts after one year on ART. We analyzed diverse routine laboratory determinations at different times using Least Absolute Shrinkage and Selection Operator (LASSO), adaptive LASSO and Conditional Inference Random Forest.
\end{abstract}

Results: CD4/CD8 ratio, \% CD4 T cells and CD8 T cell counts at different times were the main recovery correlates, validated by all approaches. Unexpectedly, basal hematocrit was a consistent predictor. Additionally, week 24 creatinine had a high lasso coefficient, and alkaline phosphatase had a high conditional inference random forest coefficients, although neither was verified by other tests.

Conclusions: CD4 T cell proportions are associated with CD4 T cell recovery, independently of cell counts. Inflammation-related variables could also affect reconstitution. These accessible variables may reflect underlying mechanisms and could improve the follow up of patients starting ART with an advanced HIV infection.

Keywords: Machine learning, HIV infections, Antiretroviral therapy, Immune reconstitution, CD4-CD8 ratio

\footnotetext{
* Correspondence: espinosa@iner.gob.mx

${ }^{\dagger}$ Dámaris P. Romero-Rodríguez and Carlos Ramírez contributed equally to this work.

${ }^{5}$ Laboratory of Integrative Immunology, Instituto Nacional de Enfermedades Respiratorias Ismael Cosío Villegas, Calzada de Tlalpan 4502, 14080 Mexico

City, Mexico

Full list of author information is available at the end of the article
}

(c) The Author(s). 2020 Open Access This article is licensed under a Creative Commons Attribution 4.0 International License, which permits use, sharing, adaptation, distribution and reproduction in any medium or format, as long as you give appropriate credit to the original author(s) and the source, provide a link to the Creative Commons licence, and indicate if changes were made. The images or other third party material in this article are included in the article's Creative Commons licence, unless indicated otherwise in a credit line to the material. If material is not included in the article's Creative Commons licence and your intended use is not permitted by statutory regulation or exceeds the permitted use, you will need to obtain permission directly from the copyright holder. To view a copy of this licence, visit http://creativecommons.org/licenses/by/4.0/. 


\section{Introduction}

Currently, about 21 million $\mathrm{HIV}^{+}$patients are accessing antiretroviral therapy (ART) [1] and face important health challenges. Even if they reach an undetectable blood viral load (VL) with ART, some of them attain a poor recovery of CD4 $\mathrm{T}$ cells in blood [2, 3]. These patients remain mostly free of opportunistic infections, but they have an increased incidence of non-AIDS defining illnesses [4]. CD4 T cell count at ART initiation is today the most usual predictor of the magnitude of recovery of CD4 T cells under ART $[5,6]$. It is thus likely that a person with HIV initiating ARV at a late phase of infection will recover CD4 $\mathrm{T}$ cells deficiently. This is aggravated by the high rate of late diagnosis in different countries and regions [7-10].

With the aim of finding variables, other than basal CD4 $\mathrm{T}$ cells count, associated with immune reconstitution, we analyzed data from a cohort of 67 patients that initiated antiretroviral therapy with very low CD4 T cell counts, using the machine learning models Least Absolute Shrinkage and Selection Operator (LASSO), adaptive LASSO and Conditional Inference Random Forest. The latter, less biased by correlations among independent variables.

\section{Patients and methods}

We utilized data from a previous study cohort $[11,12]$ of patients starting antiretroviral therapy (ART) and were followed up one year. The study was approved by our Institutional Research and Ethics Board (code C0408), and all patients signed informed consent complying with the Helsinki Declaration.

CD4 T cell and CD8 Tcell counts (TriTest kit, FACSCalibur system, Becton Dickinson, San Jose, CA, USA), and plasma VL (Cobas Amplicor-PCR-Monitor HIV-1 system, Roche Diagnostics, Indianapolis, IN, USA) were measured at the Center for Research in Infectious Diseases of our Institute. We included blood biometry, blood chemistry, and liver function tests, performed at the Clinical Laboratory of our Institute [11].

We used Least Absolute Shrinkage and Selection Operator (LASSO) as implemented in the $\mathrm{R}$ package "glmnet" with default parameters $[13,14]$ to find the main linear independent predictors of CD4 T cell recovery, which was defined as the net increment of CD4 T cells $/ \mathrm{mm}^{3}$ blood (delta CD4 $\mathrm{T}$ cells) in the first year of treatment (week $52 \mathrm{CD} 4 \mathrm{~T}$ cell counts minus basal counts). This measure was chosen because a great portion of patients did not achieve counts above 200 or 350 CD4 T cells $/ \mathrm{mm}^{3}$ blood) at week 52 , which are thresholds used to define satisfactory reconstitution.

LASSO achieves model fitting and feature selection simultaneously [15]. It was implemented using a Leave One Out Cross validation (LOOC), based on training the machine learning algorithm with $\mathrm{N}-1$ samples $(N=$ total of samples), and evaluating the adjustment with a sample not yet known by the model. The implementation of "glmnet" standardizes data by default and rescales the coefficients to be returned. Scaling is required only by this model.

LASSO analysis allows no missing values, so raw data from 99 patients (Supplementary File 1_Raw Data) were processed in order to obtain a data set with the maximal number of linear variables having no missing values. Data processing yielded 67 patients with 53 linear variables used as independent variables in the model (Supplementary File 2_Clean Data, and Supplementary File 3 Variable identification). All chosen patients had reached undetectable VL at week 52, and had available CD4 $\mathrm{T}$ cell counts at weeks 0 (basal), 8, 12, 24, 39, and 52 after treatment initiation. We included two patients with detectable low viral loads at week 52 , because they corresponded to viral blips, according to accepted definitions [16]. Both had reached undetectable viral loads on week 39, just before week 52, and had subsequent undetectable viral loads after 104 weeks on treatment.

The 53 variables comprised mainly standard routine laboratory tests, in addition to HIV treatment follow-up variables determined at fixed time points (weeks $0,8,24$, 39 , and 52 weeks). Basal age and body-mass index were also included. We excluded week 52 and basal CD4 T cell count because delta CD4 T cell (our dependent variable) is arithmetically obtained with them. Therefore, our study yields predictors additional to nadir CD4 $\mathrm{T}$ cells.

A linear regression was done using the 20 variables with the greatest LASSO coefficients (top 20 contributing to the model), as in previous studies [17, 18], with the purpose of assessing statistical significance, thus providing a simple output that is easy to interpret. The linear model used all samples at once $(N=67)$, while LASSO performed $\mathrm{N}$ iterations using $\mathrm{N}-1$ different

Table 1 Basal values for different variables of the studied cohort. IQR, inter-quartile range

\begin{tabular}{lll}
\hline Variable & Median & IQR \\
\hline Age (years) & 35 & $29.9-41.3$ \\
Body-mass index & 22 & $20.4-23.8$ \\
CD4 T cell count (cells/mm³ blood) & 48 & $21-105$ \\
\%CD4 T cells & 5 & $2.6-7$ \\
CD8 T cell count (cells/mm³ blood) & 847 & $532-1256$ \\
\%CD8 T cells & 69 & $60-76$ \\
CD4/CD8 ratio & 0.068 & $0.03-0.12$ \\
VL (HIV RNA copies/mL blood) & 328,000 & $108,000-744,000$ \\
Log VL & 5.52 & $5.03-5.87$ \\
CD4 T cell count increment in one year & 196 & $137-246$ \\
\hline
\end{tabular}


a

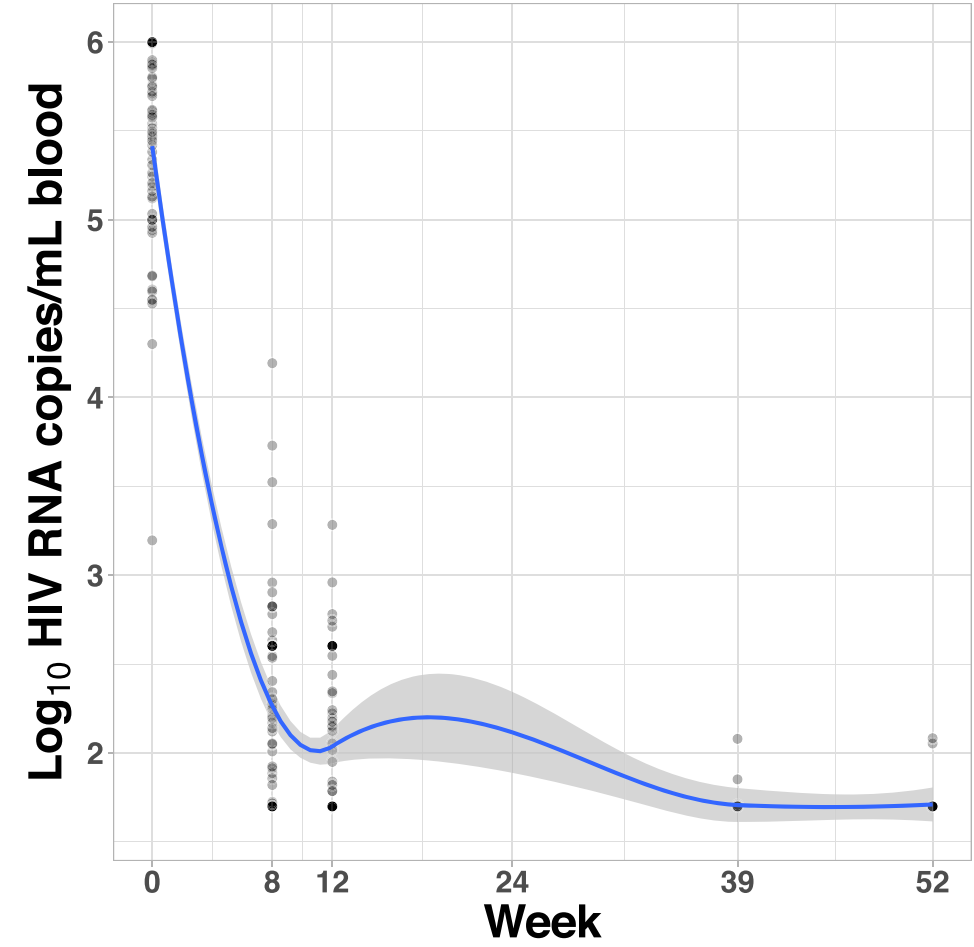

b

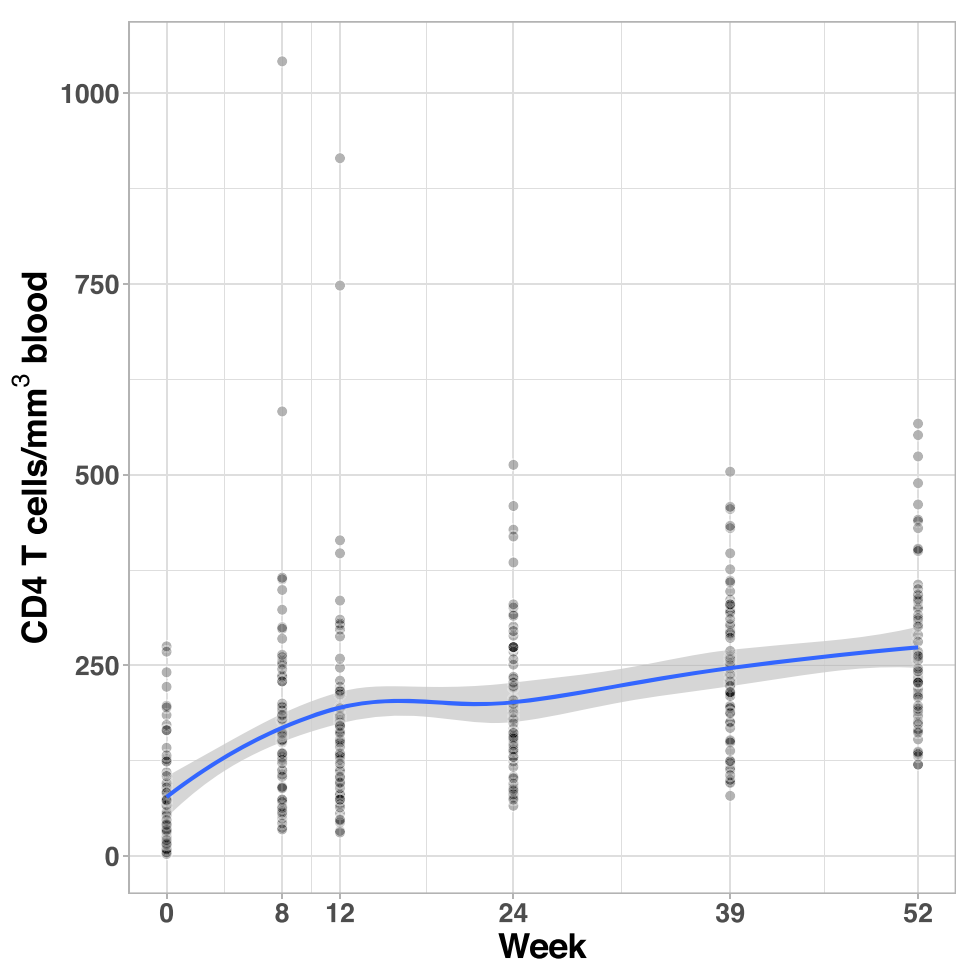

Fig. 1 Cohort's response to antiretroviral treatment over one year. $\mathbf{a}$, Viral load (HIV RNA copies $/ \mathrm{mL}$ blood). b, CD4 T cell count (cells/mm blood) 
variable sets $(\mathrm{N}-1=66)$. This provided additional validation to LASSO results.

To evaluate possible over-fitting, the linear regression used leave-one-out cross validation (given the small simple size). As with LASSO, we performed $\mathrm{N}$ linear regressions, training with $\mathrm{n}-1$ samples, plotting the predictions for the sample that was unknown to the model.

LASSO tends to group correlated variables, and randomly selects one of them and shrinks the others to zero, which may lead to over-fitting. To address this limitation, we generated a model using partial correlations with adaptive LASSO using "adalasso.net", which mitigates overfitting. We also generated a Conditional Inference Random Forest with "cforest" function of the R Package "Party", which is suitable for models involving multicollinearity. It can measure variable importance in combination (with "varimp" function), and it avoids overfitting. While LASSO assumes a linear relation, conditional inference random forest can model non-linear relationships between variables. Data analyses were performed using R 3.6.1 [14]. The scripts can be found at https://github.com/caramirezal/vihCohort/blob/master/ scripts/article_figures.R

Additionally, we performed univariate regressions of week $24 \mathrm{CD} 4 / \mathrm{CD} 8$ ratio with percentages of subpopulations of CD4 and CD8 T cells. This analysis was done using SPSS software.

\section{Results}

Basal features of patients are displayed in Table 1.

All patients reached undetectable VL at week 52 after initiating treatment (Fig. 1 A). Sixty-four patients were male and 3 female. Patients' basal CD4 T cell counts ranged from 3 to $275 \mathrm{CD} 4 \mathrm{~T}$ cells $/ \mathrm{mm}^{3}$ blood (Table 1 ). Only 17 patients had basal counts above 100 , and only 4 above 200 (Fig. 1 B).

The 20 variables with the highest LASSO coefficient included CD4/CD8 ratio at weeks $52,39,8,12$, and 24

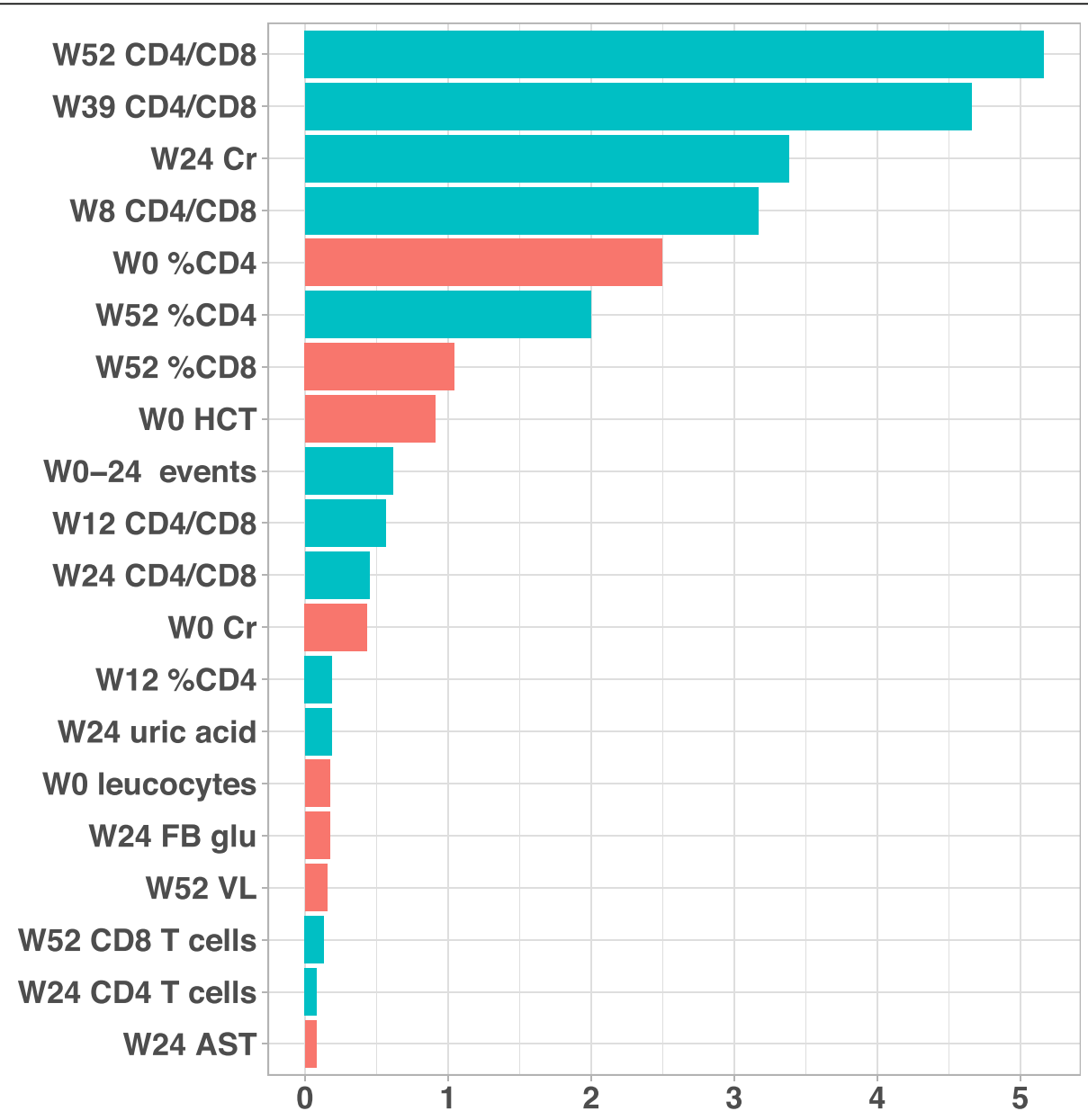

Fig. 2 LASSO-selected variables with the highest coefficients (top 20). Plotted values correspond to transformed coefficients. For each variable, the transformed value equals the natural logarithm of the absolute value plus 1. Green, coefficients with positive value. Salmon, coefficients with a negative value. W, week under treatment; Cr, serum creatinine; \%CD4, \% CD4 T cells; HCT, hematocrit; FB glu, fasting blood glucose; VL, viral load (HIV mRNA copies/mL blood); AST, Aspartate transaminase 
(Fig. 2), followed by week 24 serum creatinine, and week 8 CD4/CD8 ratio. Next, basal \%CD4 T cells (-11.09), week 52 \%CD4 T cells, week $52 \%$ CD8 T cells and basal hematocrit. All variables are shown in Supplementary File 4.

A linear model using the 20 LASSO-selected variables with the greatest coefficients (Fig. 3A, Supplementary File 5) showed a fitting of $\mathrm{R}^{2}=0.72, \mathrm{~F}=170.4, \mathrm{DF}=65$, $p<2.2 \times 10^{-16}$, while a linear model using basal CD4 T cell counts as the single independent variable did not predict the delta CD4 $\mathrm{T}$ cells (adjusted $\mathrm{R}^{2}=0.034, \mathrm{~F}=$ 3.33, DF $=65, p=0.073$, Fig. $3 \mathrm{~B}$ ).

Twelve of the major LASSO-selected variables were also selected by adaptive lasso. They comprised week 52 and $39 \mathrm{CD} 4 / \mathrm{CD} 8$ ratio, week 24 creatinine, week 8 CD4/CD8 ratio, basal \%CD4 T cells, week 52\% CD4 T cells, week 52\% CD8 T cells, basal hematocrit, week 24 $\mathrm{CD} / \mathrm{CD} 8$ ratio, basal leucocyte count, week 52 viral load and week 52 CD8 $\mathrm{T}$ cell counts. The coefficients of all variables are listed in Supplementary File 6.

Conditional inference random forest analysis yielded 26 variables with positive importance coefficients (Fig. 4). Among them, eight corresponded to major variables selected by both LASSO and adaptive LASSO: CD4/CD8 ratio at weeks 24,39 and $52, \%$ CD4 $\mathrm{T}$ cells at weeks 0 and 52, week $52 \mathrm{CD} 8 \mathrm{~T}$ cell count and percentage, as well as basal hematocrit. These eight variables are thus independently validated. Conditional inference random forest also assigned a positive coefficient to the occurrence of immune reconstitution inflammatory syndrome (IRIS) (importance coefficient $=81.06$ ), which had been selected by adaptive LASSO (coefficient $=-13.3$ ). Additionally, it assigned a positive coefficient of 345.26 to week 24 alkaline phosphatase, which was not selected by LASSO or adaptive LASSO analysis. (See the complete results in Supplementary File 7).

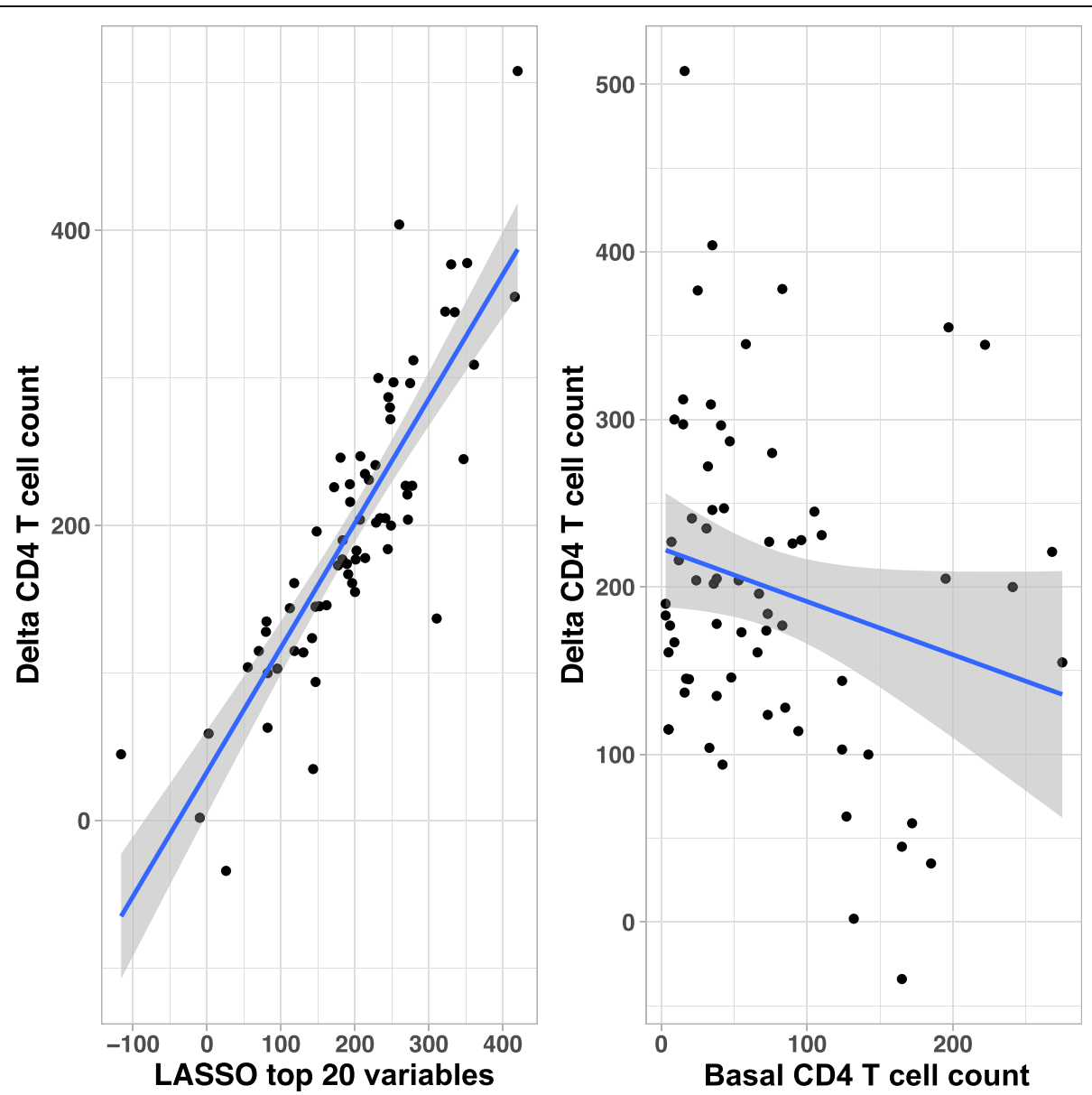

Fig. 3 Comparison of linear models using A, Top 20 LASSO variables, and B, basal CD4 T cell counts, as predictors of net increment in CD4 T cell counts after 52 weeks on ART ("delta T CD4"). For A, regression was performed using leave-one-out cross validation, performing $\mathrm{N}$ linear regressions, training with $\mathrm{N}-1$ samples, plotting the predictions for the sample that was unknown to the model. Adjusted $R^{2}=0.71960667, F=$ $170.383628(\mathrm{DF}=65) p=7.915957 \times 10^{-20}$. B, linear model with basal (week 0) CD4 T cell counts. Adjusted $R^{2}=0.034, F=3.33(D F=65), p=0.07$ 


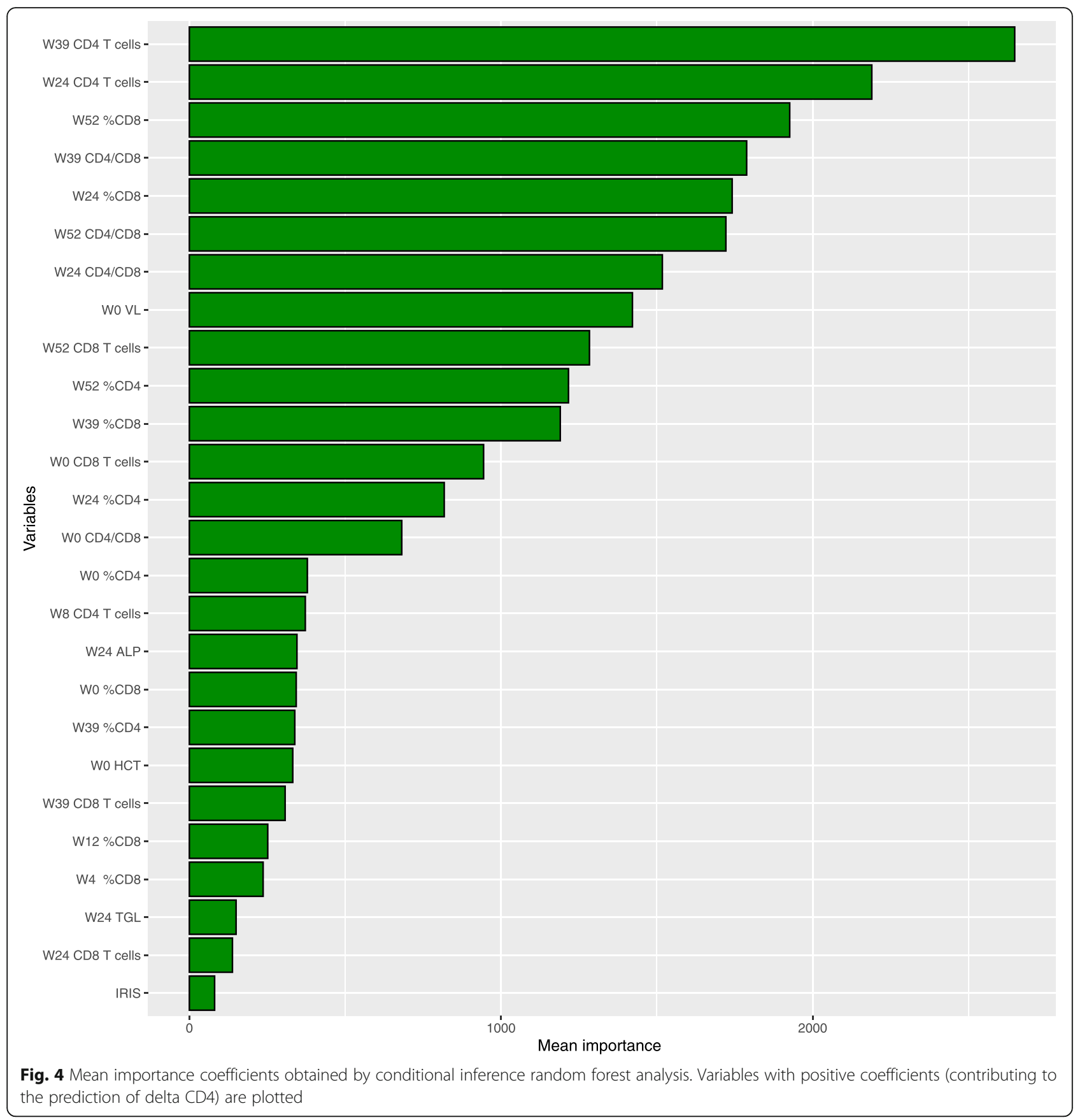

CD4/CD8 ratio values remained below 1 (known as an inverted coefficient [19]), even though they increased consistently during the whole follow up (Fig. 5).

In univariate correlations, week $24 \mathrm{CD} 4 / \mathrm{CD} 8$ ratio correlated negatively with the basal (week 0) percentage of CD28- cells among effector memory CD4 T cells, basal blood CD8 $\mathrm{T}$ cell count, week 24 percentage of activated naive $\mathrm{CD} 8 \mathrm{~T}$ cells, and week 24 percentage of $\mathrm{CD} 28^{-}$ naive $\mathrm{CD} 4 \mathrm{~T}$ cells (Table 2). Week 24 CD4/CD8 ratio positively correlated with week 24 percentage of memory CD8 T cells (Table 2).

\section{Discussion}

In many studies reconstitution is indicated by an end point count of CD4 T cells after initiation of antiretroviral treatment (ART) [20-22]. Other studies classify patients as good or poor responders according to a fixed arbitrary increase in CD4 T cell counts [23]. It is well described that initial counts predict end point ones [5, 6]. In contrast to end-point counts, our work studies the net increment in CD4 T cell counts (delta CD4 T cells), which also determines reconstitution. In the current late-presenting cohort, we found that initial CD4 $\mathrm{T}$ cell counts did not 


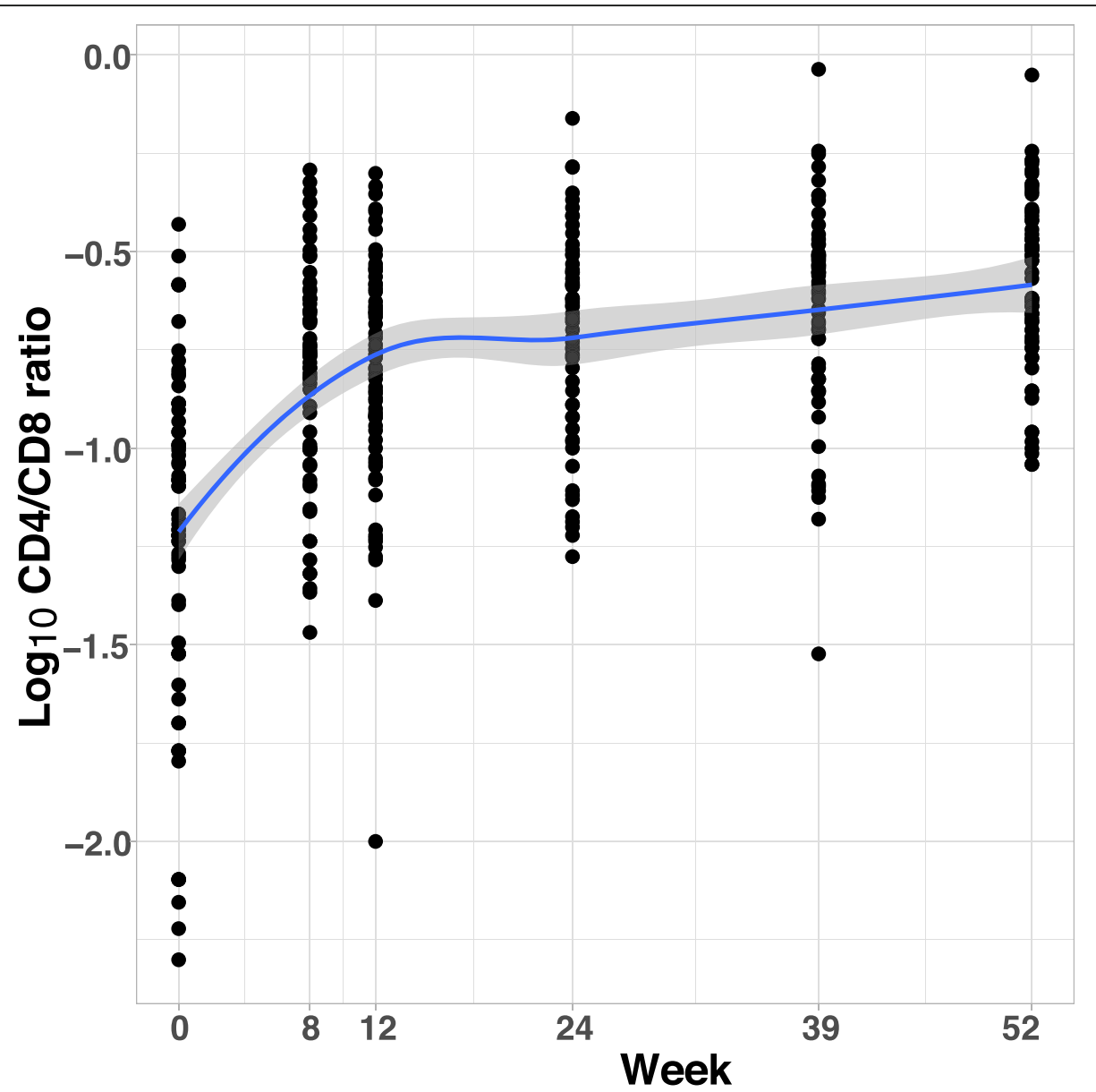

Fig. 5 CD4/CD8 ratio throughout the first year under ART. Results are presented as $\log _{10}$. Each dot corresponds to a patient's value (with possible overlapping). A smooth curve was fitted to show trends

predict the net gain of $\mathrm{CD} 4 \mathrm{~T}$ cells. By using a set of LASSO-selected variables, we built a model with a significant fit to this reconstitution variable. These variables are important because they may reflect mechanisms underlying CD4 T cell recovery. Among them, those at ART initiation or early thereafter may be further evaluated as potential predictors of $\mathrm{CD} 4 \mathrm{~T}$ cell gain.

Table 2 Phenotypes of CD4 and CD8 T cells significantly correlating with week 24 CD4/CD8 ratio. Only basal and week 24 values were analyzed. Rho values correspond to univariate Spearman correlation. $\mathrm{N}$, sample size, according to availability of data

\begin{tabular}{llll}
\hline & Rho & $p$ & $N$ \\
\hline Basal \%CD28- of effector memory CD4 T cells &,- 540 & 0.02528871 & 17 \\
Week 24\%CD38 ${ }^{+}$HLADR $^{+}$of naive CD8 T cells &,- 397 & 0.04963967 & 25 \\
Week 24\%memory of total CD8 T cells &, 408 & 0.04281341 & 25 \\
Week 24\%CD28 ${ }^{-}$of naive CD4 T cells &,- 428 & 0.04679031 & 22 \\
Basal naive CD8 T cells $/ \mathrm{mm}^{3}$ blood &,- 487 & 0.0183949 & 23 \\
\hline
\end{tabular}

Our findings extend the broad context of CD4/CD8 ratio studies. In very elderly people ( $>80$ years) without $\mathrm{HIV}$, an inverted CD4/CD8 ratio (lower than 1) was associated with increased mortality [24], increased activation of CD8 $\mathrm{T}$ cells, a shrunken $\mathrm{T}$ cell repertoire [25], low $\mathrm{CD} 4 \mathrm{~T}$ cell percentages, decreased $\mathrm{T}$ cell response to mitogens, and a greater frequency of cytomegalovirus and Epstein Barr infections [24, 26]. In the setting of untreated HIV infection, CD4/CD8 inversion was a predictor of untreated HIV infection progression [19]. In $\mathrm{HIV}^{+}$patients starting ART, CD4/CD8 was a predictor of AIDS clinical events and death [27]. It would be expectable to find a higher overall morbidity in the present cohort, which started antiretroviral treatment with a great loss of CD4 $\mathrm{T}$ cells [28].

CD4/CD8 ratio is associated with non-AIDS events in people with controlled viremia under ART $[29,30]$. In these patients, CD4/CD8 is also correlated with activation and senescence of $\mathrm{T}$ cells $[29,31]$. In our cohort, week 24 CD4/CD8 ratio (the earliest predictive variable validated by the three methods) correlated negatively with the 
contemporaneous percent of activated naive CD8 T cells and the frequency of differentiated $\left(\mathrm{CD} 28^{-}\right)$naive $\mathrm{CD} 4 \mathrm{~T}$ cells. It also correlated negatively with the basal percentages of CD28- (senescent) effector memory CD4 T cells. This positive correlation with frequencies of less differentiated subpopulations, and a negative correlation with $\mathrm{T}$ cell activation, concur with previous findings [29, 32].

Our findings extend the predictive capacity of CD4/ $\mathrm{CD} 8$ ratio to net $\mathrm{CD} 4 \mathrm{~T}$ cell recovery under ART. There are two previous studies addressing this variable. A study of 30 patients with relatively preserved $\mathrm{CD} 4 \mathrm{~T}$ cell counts found a correlation of CD4/CD8 ratio with CD4 $\mathrm{T}$ cell increment two years after ART initiation [33]. Another study did not find any association six months after ART initiation [34]. In our study of patients starting ART with profound CD4 $\mathrm{T}$ cell loss, CD4/CD8 ratio at weeks 24, 39 and 52 were associated with absolute CD4 $\mathrm{T}$ cell gain, according to three machine learning methods.

It is noteworthy that in our advanced-stage cohort, proportions of $\mathrm{CD} 4 \mathrm{~T}$ cells were major correlates of CD4 $\mathrm{T}$ cell gain. Percent CD8 T cells and \% CD4 T cells, as well as basal \%CD4 $\mathrm{T}$ cells were consistently associated with $\mathrm{CD} 4$ $\mathrm{T}$ cell recovery by all models. Moreover, week $52 \mathrm{CD} 8 \mathrm{~T}$ cell counts, which determine CD4/CD8 ratio, were among these variables. In this regard, CD8 T cells are expanded in HIV disease [35-37]. These findings suggest a possible independence of CD4 T cell proportions as correlates of immune recovery. In line with this possible independence, CD4/CD8 ratio correlated with $\mathrm{CD} 4 \mathrm{~T}$ cell increment after two years on ART, even though basal CD4 T cell counts did not correlate with $\mathrm{CD} 4 \mathrm{~T}$ cell increment [33]. Interestingly, the patients in this study had basal CD4 $\mathrm{T}$ cell counts significantly higher than our cohort (median 380, IQR 310-500, Mann Whitney $\mathrm{U}=81, p<0.001$ ), suggesting a broad predictive capacity of CD4/CD8 ratio. Our findings extend the disadvantage of a low $\mathrm{CD} 4 / \mathrm{CD} 8$ ratio, which is already known to predict the incidence of non-AIDS-defining illnesses, even when CD4 T cells counts are normal [38], and even when the analysis is adjusted for CD4 T cell counts [29].

Basal hematocrit was selected by the two LASSO models, with a negative coefficient, and had a positive importance coefficient in conditional inference random forest analysis. Values ranged between 27.3 to 53.8 , mostly within our Institute reference values (37-54), and there were no signs of anemia in the cohort. Whether hematocrit is reflecting a mechanism altering CD4 $\mathrm{T}$ cell recovery requires further research. This routine laboratory determination might help detecting patients with a higher risk of poor reconstitution.

The occurrence of immune reconstitution inflammatory syndrome (IRIS) was selected by adaptive LASSO and by conditional inference random forest (81.1). Also indicating inflammation, week 24 alkaline phosphatase was selected by conditional inference random forest, but was not selected by LASSO models. In univariate regression, it correlated negatively with delta CD4 $\mathrm{T}$ cells (Spearman's Rho $=$ $-0.25, p=0.04$ ). A deleterious effect of inflammation on immune reconstitution under ART has been described [39, 40], and could be related with CD4/CD8 ratio [31].

A limitation of our study is the lack of additional measures of model performance, like OOB error for Conditional Inference Random Forest. Nevertheless, the consistency between different algorithms supports the importance of our variables.

\section{Conclusion}

Among patients initiating ART in a very advanced stage of HIV infection, proportions of CD4 T cells are associated with the immunological response to antiretroviral therapy, possibly reflecting reconstitution determinants other than initial CD4 $\mathrm{T}$ cell counts. Together with IRIS and alkaline phosphatase, they comprise a set of accessible variables that could be used to predict the response to antiretroviral therapy.

\section{Supplementary information}

Supplementary information accompanies this paper at https://doi.org/10. 1186/s41231-020-00058-x.

\section{Additional file 1. \\ Additional file 2. \\ Additional file 3. \\ Additional file 4. \\ Additional file 5. \\ Additional file 6 . \\ Additional file 7.}

\section{Abbreviations}

ALP: Alkaline phosphatase; AST: Aspartate transaminase; ART: antiretroviral therapy; Cr: Creatinine; FB glu: Fasting basal glucose; HCT: Hematocrit; IRIS: Immune reconstitution inflammatory syndrome; LASSO: Least Absolute Shrinkage and Selection Operator; VL: Viral load; W: Week; TGL: Triglycerides; TCM: Central memory CD4 T cells

Acknowledgements

D.P. R-R and C.R contributed equally to this work.

\section{Authors' contributions}

DPR-R performed cohort follow up and sample collection, organized patient visits, medical staff collection of data, prepared samples, did the flow cytometry analysis of patient's cells and analyzed some of the plasma variables. CR performed data analysis. II-R analyzed data, CEO analyzed data, AP-P was the attending physician and collected the clinical data, GO-G, FC, JRR, and DW-M performed laboratory determinations, WJ designed the study, interpreted results and wrote the manuscript, GRT conceived and designed the study, followed up patients, EE conceived and designed the study, interpreted results, analyzed data, and wrote the manuscript. The author(s) read and approved the final manuscript.

\section{Funding}

This work was financed by grant NIAID Al-1288864, U. S. A. (WJ.), grant 24011 (P50478) from the Mexican National Research and Technology Council (CONACyT) (E. E.), and grants from the Mexican Government (Comisión de Equidad y Género de las Legislaturas LX-LXI y Comisión de lgualdad de Género de la Legislatura LXII de la H. Cámara de Diputados de la República Mexicana) (G. R-T.). 


\section{Availability of data and materials}

The code and datasets generated and analysed during the current study are available in the github repository.

https://github.com/caramirezal/vihCohort/blob/master/scripts/article_figures.R

\section{Ethics approval and consent to participate}

The study was approved by our Institutional Research and Ethics Board (registration number C04-08), and all patients signed informed consent in agreement with the Helsinki Declaration.

\section{Consent for publication}

Not applicable.

\section{Competing interests}

The authors declare that they have no competing interests.

\section{Author details}

${ }^{1}$ Cell Cytometry Core Facility, Instituto Nacional de Enfermedades Respiratorias Ismael Cosío Villegas, Mexico City, Mexico. ${ }^{2}$ Department of Molecular Biology and Biotechnology, Instituto de Investigaciones Biomédicas, Universidad Nacional Autónoma de México, Mexico City, Mexico. ${ }^{3}$ Wellcome -MRC Cambridge Stem Cell Institute and Department of Haematology, University of Cambridge, Cambridge, UK. ${ }^{4}$ Center for Infectious Diseases Research (CIENI), Instituto Nacional de Enfermedades Respiratorias Ismael Cosío Villegas, Mexico City, Mexico. ${ }^{5}$ Laboratory of Integrative Immunology, Instituto Nacional de Enfermedades Respiratorias Ismael Cosío Villegas, Calzada de Tlalpan 4502, 14080 Mexico City, Mexico. ${ }^{6}$ Department of Microbiology and Immunology, Division of Infectious Diseases, Department of Medicine, Medical University of South Carolina, Charleston, SC, USA.

Received: 1 October 2019 Accepted: 24 March 2020

Published online: 23 April 2020

\section{References}

1. UNAIDS. Fact Sheet-World AIDS Day 2017 [Internet]. UNAIDS. 2017 [cited 2018 Feb 5]. Available from: http://www.unaids.org.

2. Lederman HM, Williams PL, Wu JW, Evans TG, Cohn SE, McCutchan JA, et al. Incomplete immune reconstitution after initiation of highly active antiretroviral therapy in human immunodeficiency virus-infected patients with severe CD4+ cell depletion. J Infect Dis. 2003;188(12):1794-803.

3. Kelly C, Gaskell KM, Richardson M, Klein N, Garner P, MacPherson P. Discordant immune response with antiretroviral therapy in HIV-1: a systematic review of clinical outcomes. PLoS One. 2016;11(6):e0156099.

4. Zoufaly A, Cozzi-Lepri A, Reekie J, Kirk O, Lundgren J, Reiss P, et al. Immunovirological discordance and the risk of non-AIDS and AIDS events in a large observational cohort of HIV-patients in Europe. PLoS One. 2014;9(1):e87160.

5. Mutoh Y, Nishijima T, Inaba Y, Tanaka N, Kikuchi Y, Gatanaga H, et al. Incomplete recovery of CD4 cell count, CD4 percentage, and CD4/CD8 ratio in patients with human immunodeficiency virus infection and suppressed Viremia during long-term antiretroviral therapy. Clin Infect Dis Off Publ Infect Dis Soc Am. 2018;67(6):927-33.

6. Gras L, May M, Ryder LP, Trickey A, Helleberg M, Obel N, et al. Determinants of Restoration of CD4 and CD8 Cell Counts and Their Ratio in HIV-1-Positive Individuals With Sustained Virological Suppression on Antiretroviral Therapy. J Acquir Immune Defic Syndr 1999. 2019:80(3):292-300.

7. Martin-Onraët A, Volkow-Fernández P, Alvarez-Wyssmann V, GonzálezRodríguez A, Casillas-Rodríguez J, Rivera-Abarca L, et al. Late diagnosis due to missed opportunities and inadequate screening strategies in HIV infected Mexican women. AIDS Behav. 2017;21(2):505-14.

8. Rampaul M, Edun B, Gaskin M, Albrecht H, Weissman S. Cost-effectiveness analysis of early vs late diagnosis of HIV-infected patients in South Carolina. South Med J. 2018;111(6):355-8.

9. Wilton J, Light L, Gardner S, Rachlis B, Conway T, Cooper C, et al. Late diagnosis, delayed presentation and late presentation among persons enrolled in a clinical HIV cohort in Ontario, Canada (1999-2013). HIV Med. 2019;20(2):110-20.

10. Gargallo-Bernad C, Sangrós-González FJ, Arazo-Garcés P, Martínez-Álvarez R, Malo-Aznar C, Gargallo-Bernad A, et al. Missed opportunities in the diagnosis of human immunodeficiency virus infection in the region of Aragon. Late diagnosis importance. Enferm Infecc Microbiol Clin. 2019;37(2): 100-8.
11. Espinosa E, Ormsby CE, Vega-Barrientos RS, Ruiz-Cruz M, Moreno-Coutino G, Pena-Jimenez A, et al. Risk factors for immune reconstitution inflammatory syndrome under combination antiretroviral therapy can be aetiologyspecific. Int J STD AIDS. 2010;21(8):573-9.

12. Espinosa E, Romero-Rodríguez DP, Cantoral-Díaz M-T, Reyes-Terán G. Transient expansion of activated CD8+ T cells characterizes tuberculosisassociated immune reconstitution inflammatory syndrome in patients with HIV: a case control study. J Inflamm Lond Engl. 2013;10(1):21.

13. Friedman J, Hastie T, Tibshirani R. Regularization paths for generalized linear models via coordinate descent. J Stat Softw. 2010;33(1):1-22.

14. Core R. Team. R: a language and environment for statistical computing [internet]. Viena: R Foundation for statistical. Computing. 2013; Available from: http://www.R-project.org/.

15. Tibshirani R. Regression shrinkage and selection via the lasso. J R Stat Soc Ser B Methodol. 1996:58(1):267-88.

16. Sörstedt E, Nilsson S, Blaxhult A, Gisslén M, Flamholc L, Sönnerborg A, et al. Viral blips during suppressive antiretroviral treatment are associated with high baseline HIV-1 RNA levels. BMC Infect Dis. 2016;21(16):305.

17. Mueller-Using S, Feldt T, Sarfo FS, Eberhardt KA. Factors associated with performing tuberculosis screening of HIV-positive patients in Ghana: LASSObased predictor selection in a large public health data set. BMC Public Health. 2016;13(16):563.

18. Muenchhoff M, Healy M, Singh R, Roider J, Groll A, Kindra C, et al. Malnutrition in HIV-infected children is an Indicator of severe disease with an impaired response to antiretroviral therapy. AIDS Res Hum Retrovir. 2018; 34(1):46-55.

19. Margolick JB, Gange SJ, Detels R, O'Gorman MRG, Rinaldo CR, Lai S. Impact of inversion of the CD4/CD8 ratio on the natural history of HIV-1 infection. J Acquir Immune Defic Syndr 1999. 2006;42(5):620-6.

20. Anthony KB, Yoder C, Metcalf JA, DerSimonian R, Orenstein JM, Stevens RA, et al. Incomplete CD4 T cell recovery in HIV-1 infection after 12 months of highly active antiretroviral therapy is associated with ongoing increased CD4 T cell activation and turnover. J Acquir Immune Defic Syndr. 2003;33(2):125-33.

21. Marchetti G, Gori A, Casabianca A, Magnani M, Franzetti F, Clerici M, et al. Comparative analysis of T-cell turnover and homeostatic parameters in HIVinfected patients with discordant immune-virological responses to HAART. AIDS Lond Engl. 2006;20(13):1727-36.

22. Gómez-Mora E, Massanella M, García E, Giles D, Bernadó M, Urrea V, et al. Elevated humoral response to cytomegalovirus in HIV-infected individuals with poor CD4+ T-cell immune recovery. PLoS One. 2017;12(9):e0184433.

23. Batista G, Buvé A, Ngom Gueye NF, Manga NM, Diop MN, Ndiaye K, et al. Initial suboptimal CD4 reconstitution with antiretroviral therapy despite full viral suppression in a cohort of HIV-infected patients in Senegal. Med Mal Infect. 2015;45(6):199-206.

24. Wikby A, Maxson P, Olsson J, Johansson B, Ferguson FG. Changes in CD8 and CD4 lymphocyte subsets, T cell proliferation responses and non-survival in the very old: the Swedish longitudinal OCTO-immune study. Mech Ageing Dev. 1998;102(2-3):187-98.

25. Hadrup SR, Strindhall J, Køllgaard T, Seremet T, Johansson B, Pawelec G, et al. Longitudinal studies of clonally expanded CD8 T cells reveal a repertoire shrinkage predicting mortality and an increased number of dysfunctional cytomegalovirus-specific T cells in the very elderly. J Immunol Baltim Md 1950. 2006;176(4):2645-53.

26. Wikby A, Ferguson F, Forsey R, Thompson J, Strindhall J, Löfgren S, et al. An immune risk phenotype, cognitive impairment, and survival in very late life: impact of allostatic load in Swedish octogenarian and nonagenarian humans. J Gerontol A Biol Sci Med Sci. 2005;60(5):556-65.

27. Bonnet $F$, Thiébaut $R$, Chêne $G$, Neau D, Pellegrin J-L, Mercié $P$, et al. Determinants of clinical progression in antiretroviral-naive HIV-infected patients starting highly active antiretroviral therapy. Aquitaine cohort, France, 1996-2002. HIV Med. 2005;6(3):198-205.

28. Rodríguez Arrondo F, von Wichmann MÁ, Camino X, Goenaga MÁ, Ibarguren $M$, Azcune $H$, et al. A case-control study of non-AIDS-defining cancers in a prospective cohort of HIV-infected patients. Med Clin (Barc) 2018 23;150(8):291-296.

29. Serrano-Villar S, Sainz T, Lee SA, Hunt PW, Sinclair E, Shacklett BL, et al. HIVinfected individuals with low CD4/CD8 ratio despite effective antiretroviral therapy exhibit altered T cell subsets, heightened CD8+ T cell activation, and increased risk of non-AIDS morbidity and mortality. PLoS Pathog. 2014; 10(5):e1004078. 
30. Mussini C, Lorenzini P, Cozzi-Lepri A, Lapadula G, Marchetti G, Nicastri E, et al. CD4/CD8 ratio normalisation and non-AIDS-related events in individuals with HIV who achieve viral load suppression with antiretroviral therapy: an observational cohort study. Lancet HIV. 2015;2(3):e98-106.

31. Sainz T, Serrano-Villar S, Díaz L, González Tomé MI, Gurbindo MD, de José $\mathrm{MI}$, et al. The CD4/CD8 ratio as a marker T-cell activation, senescence and activation/exhaustion in treated HIV-infected children and young adults. AIDS Lond Engl. 2013;27(9):1513-6.

32. Serrano-Villar S, Gutiérrez C, Vallejo A, Hernández-Novoa B, Díaz L, Abad Fernández $\mathrm{M}$, et al. The CD4/CD8 ratio in HIV-infected subjects is independently associated with T-cell activation despite long-term viral suppression. J Inf Secur. 2013;66(1):57-66.

33. Buggert M, Frederiksen J, Noyan K, Svärd J, Barqasho B, Sönnerborg A, et al. Multiparametric bioinformatics distinguish the $C D 4 / C D 8$ ratio as a suitable laboratory predictor of combined T cell pathogenesis in HIV infection. J Immunol Baltim Md 1950. 2014;192(5):2099-108.

34. Castagna A, Galli L, Torti C, D'Arminio Monforte A, Mussini C, Antinori A, et al. Predicting the magnitude of short-term CD4+ T-cell recovery in HIVinfected patients during first-line highly active antiretroviral therapy. Antivir Ther. 2010;15(2):165-75.

35. Nasi A, Chiodi F. Mechanisms regulating expansion of CD8+ T cells during HIV-1 infection. J Intern Med. 2018;283(3):257-67.

36. Mudd JC, Lederman MM. CD8 T cell persistence in treated HIV infection. Curr Opin HIV AIDS. 2014;9(5):500-5.

37. Freeman ML, Mudd JC, Shive CL, Younes S-A, Panigrahi S, Sieg SF, et al. CD8 T-cell expansion and inflammation linked to CMV Coinfection in ART-treated HIV infection. Clin Infect Dis Off Publ Infect Dis Soc Am. 2016;62(3):392-6.

38. Riangwiwat T, Kohorn LB, Chow DC, Souza SA, Ndhlovu LC, Wong JWH, et al. CD4/CD8 Ratio Predicts Peripheral Fat in HIV-Infected Population. J Acquir Immune Defic Syndr 1999. 2016;72(1):e17-9.

39. Shive CL, Clagett B, McCausland MR, Mudd JC, Funderburg NT, Freeman ML, et al. Inflammation Perturbs the IL-7 Axis, Promoting Senescence and Exhaustion that Broadly Characterize Immune Failure in Treated HIV Infection. J Acquir Immune Defic Syndr 1999. 2016;71(5):483-92.

40. Lederman MM, Calabrese L, Funderburg NT, Clagett B, Medvik K, Bonilla H, et al. Immunologic failure despite suppressive antiretroviral therapy is related to activation and turnover of memory CD4 cells. J Infect Dis. 2011; 204(8):1217-26.

\section{Publisher's Note}

Springer Nature remains neutral with regard to jurisdictional claims in published maps and institutional affiliations.

Ready to submit your research? Choose BMC and benefit from:

- fast, convenient online submission

- thorough peer review by experienced researchers in your field

- rapid publication on acceptance

- support for research data, including large and complex data types

- gold Open Access which fosters wider collaboration and increased citations

- maximum visibility for your research: over $100 \mathrm{M}$ website views per year

At $\mathrm{BMC}$, research is always in progress.

Learn more biomedcentral.com/submissions 